\title{
Conforto térmico de equinos alojados em diferentes tipos de baias
}

\author{
Thermal comfort of horses housed in different types of stalls
}

\author{
Geruza Cardoso da Silva, Cinara da Cunha Siqueira Carvalho", Camila Maida de Albuquerque \\ Maranhão, Maria Dulcinéia da Costa, Shirley Nunes Silva Brito, Anna Luísa de Oliveira Castro, Kátia \\ Cristiane Borges Pereira \& Thamara Amaral Diniz
}

${ }^{1}$ Universidade Estadual de Montes Claros, Montes Claros, MG, Brasil. *Autor para correspondência: cinarasiqueira@yahoo.com.br.

Submissão: 13/01/2017 | Aceite: 13/06/2018

\begin{abstract}
RESUMO
Objetivou-se avaliar o efeito das condições climáticas proporcionado por dois tipos de baias sobre as respostas fisiológicas e comportamentais de equinos por ocasião de exposição agropecuária. $\mathrm{O}$ trabalho foi desenvolvido durante os anos de 2014 e 2015 em Feira Agropecuária localizada na região do semiárido mineiro. Foi observado o ambiente climático, local de acomodação, variáveis fisiológicas e comportamentais de 114 equinos da raça Mangalarga Marchador, alojados em baias individuais de metal e alvenaria. Foram monitoradas as variáveis meteorológicas no interior das baias de metal e de alvenaria. As variáveis fisiológicas foram caracterizadas por meio da frequência respiratória e temperatura corporal. Para análise comportamental, observou-se a frequência de ocorrência de ações de defecação, micção, relinchar, agitação, ingestão de alimentos e água, às $8 \mathrm{~h}, 10 \mathrm{~h}, 12 \mathrm{~h}, 14 \mathrm{~h}, 16 \mathrm{~h}$ e $18 \mathrm{~h} . \mathrm{O}$ ambiente térmico foi classificado como de desconforto térmico a partir das $10 \mathrm{~h}$. A frequência respiratória e a temperatura corporal estiveram fora dos valores considerados ideais. A baia de metal proporcionou maior desconforto térmico para os equinos.
\end{abstract}

PALAVRAS-CHAVE: ambiência, alojamento, equídeos, Mangalarga Marchador.

\begin{abstract}
The objective of this study was to evaluate the effect of climatic conditions provided by two types of stalls on the physiological and behavioral responses of horses during agricultural exposure. The study was developed during 2014 and 2015 in an Agricultural Fair located in the semiarid region of the state of Minas Gerais, Brazil. Climatic environment, place of accommodation, physiological and behavioral variables of 114 Mangalarga Marchador horses, housed in individual metal and masonry stalls, were observed. Meteorological variables inside the metal and masonry stalls were monitored. Physiological variables were characterized by respiratory rate and body temperature. For behavioral analysis, the frequency of occurrence of defecation, urination, neigh, agitation, food and water intake were observed at $8 \mathrm{am}, 10 \mathrm{am}$, $12 \mathrm{pm}, 14 \mathrm{pm}, 16 \mathrm{pm}$ and $18 \mathrm{pm}$. The thermal environment was classified as thermal discomfort from 10 am. Respiratory rate and body temperature were outside ideal values. The metal stall caused greater thermal discomfort for horses.
\end{abstract}

KEYWORDS: ambience, housing, equine, Mangalarga Marchador horses.

\section{INTRODUÇÃO}

O agronegócio é uma atividade de grande importância para a economia nacional e no intuito de disseminar o setor pelo Brasil, exposições e feiras agropecuárias são realizadas, a fim de estimular o seu desenvolvimento em todos os segmentos produtivos. As feiras apresentam o perfil e interesse econômico da região, além de levar em consideração, os aspectos da região, sendo que algumas têm como ponto principal a exposição de animais, tanto para divulgação da genética como para comercialização (HUSS \& SILVA 2013).

Contudo, o estresse proporcionado pelo transporte, os tipos de acomodações, acesso à alimentação e hidratação, bem como as condições climáticas podem influenciar de forma negativa no comportamento, no conforto térmico e principalmente no bem-estar dos animais (BROOM 1991, PIMENTEL et al. 2013, NAZARENO et al. 2015).

Durante a realização das feiras agropecuárias, os equinos ficam alojados em diferentes tipos de 
baias, com as de alvenaria, de madeira, metal ou pequenas construções de pilares e divisórias de madeiras com cobertura de sombrite. Independente do material, a baia deve atender a certos cuidados, como: tamanho apropriado para a raça, ventilação adequada, conforto térmico, possibilitar o contato entre os animais e segurança para os mesmos (CINTRA 2010).

Neste sentido, as edificações onde os equinos ficam acomodados durante o período em que serão julgados em um parque de exposição possuem importante papel, uma vez que são construídos de diferentes materiais e que por vezes proporcionam ou não um ambiente termicamente adequado. Dessa forma, objetivou-se avaliar as respostas fisiológicas e comportamentais de equinos da raça Mangalarga Marchador, alojados em dois diferentes tipos de baias por ocasião de realização de feira agropecuária no semiárido mineiro.

\section{MATERIAL E MÉTODOS}

O trabalho foi desenvolvido durante dois anos consecutivos em Feira Agropecuária na região do semiárido mineiro. Os dados foram coletados no período de 3 a 7 de junho de 2014 e nos dias 2 a 6 de junho de 2015. Foram utilizados 114 animais da raça Mangalarga Marchador distribuídos em 12 tratamentos em esquema fatorial $2 \times 6$, sendo dois tipos de baias com dimensões diferentes (alvenaria e metal) e seis horários de avaliação ( 8 h, 10 h, 12 h, 14 h, 16 h e 18 h).

Foi observado o ambiente de acomodação, os parâmetros fisiológicos e comportamentais dos 114 equinos que participavam da competição da raça. No ano de 2014 observou-se 30 animais alojados em baias de alvenaria, sendo 22 machos e 8 fêmeas e 23 em baias de metal, 6 machos e 17 fêmeas, a faixa etária dos animais das entre 15 e 87 meses. Em 2015, foram 28 animais alojados nas baias de alvenaria, 23 machos e 5 fêmeas e 33 nas baias de metal, 4 machos e 29 fêmeas com faixa etária entre 15 a 151 meses de idade. Todos os animais ao entrarem no parque de exposição foram devidamente examinados e observados por um médico veterinário e uma equipe de estudantes de Zootecnia.

As edificações de alvenaria apresentam $30,7 \mathrm{~m}$ de comprimento, $11 \mathrm{~m}$ de largura e $5 \mathrm{~m}$ de pé-direito, com cobertura composta por engradamento de madeira e telhas de cerâmica, sendo uma estrutura fixa do local. Essas instalações são subdividas em baias individuais de 3,5 m de comprimento e 2,85 m de largura, totalizando uma área de aproximadamente $10 \mathrm{~m}^{2}$ (Figura 1).

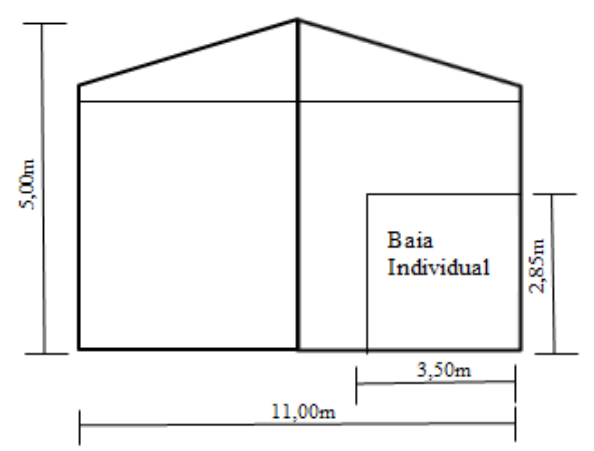

A

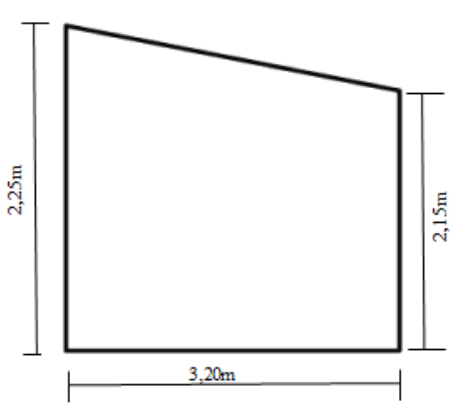

B

Figura 1. Baia de alvenaria $(A)$ e de metal (B), croqui demonstrativo da inclinação e pé direito das edificações.

Figure 1. Masonry $(A)$ and metal $(B)$ stalls, and demonstrative sketch of the slope and ceiling height of the buildings.

As edificações de metal apresentam 31,3 m de comprimentos, 3,2 $\mathrm{m}$ de largura, pé-direito frontal de $2,25 \mathrm{~m}$ e pé-direito posterior de 2,15 $\mathrm{m}$. Essas instalações também foram subdividas em baias individuais de $2,5 \times 3,2 \mathrm{~m}$, área total de $8 \mathrm{~m}^{2}$. A cobertura dessas instalações é composta por telhas de zinco. As baias de metal foram pintadas de preto na parte interna e externa. As estruturas de metal são alugadas e são utilizadas em todo o Brasil.

A caracterização do ambiente térmico foi obtida a partir da chegada no recinto às $8 \mathrm{~h}$ com término às $18 \mathrm{~h}$ e monitorada a cada $2 \mathrm{~h}$, por meio do uso de equipamento Dataloggers Extech RHT10 de leitura contínua. Foram coletadas as seguintes variáveis: temperatura de bulbo seco (TBS), temperatura de bulbo úmido (TBU), temperatura de globo negro (TGN) e velocidade do vento (VV). Os equipamentos foram 
colocados no interior das baias de alvenaria e de metal, e posicionados à $1,70 \mathrm{~m}$ de distância do solo.

De posse dos dados climáticos coletados calculou-se o Índice de Temperatura de Globo Negro e Umidade (ITGU) proposto por BUFFINGTON et al. (1981), para cada tipologia de edificação por meio do uso da equação 1.

$$
\mathrm{ITGU}=\operatorname{Tgn}+0,36 \mathrm{Tpo}+41,5 \quad \text { Equação } 1
$$

Em que: ITGU = Índice de Temperatura de Globo Negro e Umidade, TGN = Temperatura de globo negro $\left({ }^{\circ} \mathrm{C}\right)$ e TPO $=$ Temperatura do ponto de orvalho $\left({ }^{\circ} \mathrm{C}\right)$.

Os parâmetros fisiológicos foram aferidos diariamente às $8 \mathrm{~h}, 10 \mathrm{~h}, 12 \mathrm{~h}, 14 \mathrm{~h}, 16 \mathrm{~h}$ e $18 \mathrm{~h}$, por meio da caracterização da frequência respiratória (FR) e temperatura de superfície corporal (TSC). A FR foi obtida a partir da observação visual direta e quantificação dos movimentos do flanco por 15 segundos. Para a TSC foi utilizado um termômetro de infravermelho CASON CA380, com a distância de 1,5 metros do animal e do avaliador, posicionado na região da garupa, tronco e cabeça, dos animais dentro de suas baias.

$\mathrm{O}$ comportamento dos animais no interior das baias foi observado às $10 \mathrm{~h}, 12 \mathrm{~h}, 14 \mathrm{~h}, 16 \mathrm{~h}$ e $18 \mathrm{~h}$. Nas baias, o mesmo avaliador ao se aproximar da edificação observou a ocorrência das seguintes ações por cerca de 1 minuto para cada animal: defecação, micção, relinchar, agitação, indócil (agressivo, querendo morder, coices), movimentando em círculos na baia, mordendo o balde de água, ou qualquer outra estereotipia), ingestão de alimentos (consumindo ração ou feno que era fornecido de manhã e no fim da tarde pelo seus tratadores) e água. O alimento e a água eram fornecidos no início da manhã, antes do julgamento e no final do dia, depois do julgamento.

O experimento apresentou delineamento inteiramente casualizado (DIC) com esquema fatorial $2 \times 6$, sendo dois tipos de baias com dimensões diferente (alvenaria e metal) e seis horários de avaliação ( $8 \mathrm{~h}, 10$ $\mathrm{h}, 12 \mathrm{~h}, 14 \mathrm{~h}, 16 \mathrm{~h}$ e $18 \mathrm{~h}$ ), com um total de 114 animais. Os resultados foram submetidos à análise de variância, considerando como fontes de variação, os horários e as edificações, e suas interações, testados a $5 \%$ de probabilidade $(p<0,05)$. A interação foi desdobrada, ou não, de acordo com a significância e o efeito do horário foi avaliado por análise de regressão, por meio de polinômios ortogonais, pela decomposição da soma de quadrado do intervalo em efeito linear, quadrático. As edificações foram comparadas pelo teste F. As variáveis foram estudadas utilizando o pacote estatístico SISVAR.

\section{RESULTADOS E DISCUSSÃO}

A temperatura do ar foi caracterizada como de conforto até às $10 \mathrm{~h}$ nas baias de alvenaria. A zona de conforto térmico é definida como sendo a temperatura do ar ambiente na qual a taxa metabólica é constante, variando de 5 a $25^{\circ} \mathrm{C}$ (MORGAN 1996). Houve diferença significativa $(p<0,0001)$ para interação entre baia e horário (Tabela 1).

Tabela 1. Valores médios de temperatura do $\operatorname{ar}\left({ }^{\circ} \mathrm{C}\right)$, umidade relativa (\%) e ITGU ao longo do dia durante a Exposição Agropecuária.

Table 1. Mean air temperature $\left({ }^{\circ} \mathrm{C}\right)$, relative humidity (\%) and $B G T$ values throughout the day during the

\begin{tabular}{|c|c|c|c|c|c|c|c|c|}
\hline \multirow{2}{*}{ Baias } & \multicolumn{6}{|c|}{ Temperatura do ar $\left({ }^{\circ} \mathrm{C}\right)$} & \multirow[t]{2}{*}{ Equações } & \multirow[t]{2}{*}{$R^{2}(\%)$} \\
\hline & 8 & 10 & 12 & 14 & 16 & 18 & & \\
\hline Alvenaria & $22,5 b$ & $24,2 b$ & $26,5 a$ & $29,8 a$ & $28,5 a$ & $26,3 a$ & $\hat{Y}=-4,3995+4,4929 x-0,1515 x^{2}$ & 83,84 \\
\hline Metal & $32,6 a$ & $28,1 \mathrm{a}$ & $29,6 a$ & $31,9 a$ & $27,6 a$ & $26,1 \mathrm{a}$ & $\hat{Y}=21,9943+2,0201 x-0,0986 x^{2}$ & 83,42 \\
\hline \multirow[t]{2}{*}{ Média } & 27,5 & 26,1 & 28,0 & 30,9 & 28,0 & 26,2 & $\mathrm{CV}(\%)$ & 7,96 \\
\hline & \multicolumn{6}{|c|}{ Umidade Relativa (\%) } & & \\
\hline Alvenaria & $91,8 b$ & $82,5 b$ & $73,0 \mathrm{~b}$ & $64,8 b$ & $59,7 \mathrm{~b}$ & $78,3 b$ & $\hat{Y}=-206,388+19,0775 x-0,6463 x^{2}$ & 84,24 \\
\hline Metal & $49,0 \mathrm{a}$ & $55,8 \mathrm{a}$ & $49,1 \mathrm{a}$ & $46,9 a$ & $51,1 a$ & $59,2 a$ & $\hat{Y}=92,5965+5,6862 x-0,2352 x^{2}$ & 44,53 \\
\hline \multirow[t]{2}{*}{ Média } & 70,4 & 69,2 & 61,0 & 55,9 & 55,4 & 68,8 & $\mathrm{CV}(\%)$ & 13,55 \\
\hline & \multicolumn{4}{|c|}{ ITGU } & & & Média & $\mathrm{R}^{2}(\%)$ \\
\hline Alvenaria & 72,5 & 75,3 & 77,2 & 79,7 & 79,6 & 77,2 & & \\
\hline Metal & 60,0 & 81,4 & 80,1 & 79,9 & 74,9 & 73,5 & & \\
\hline Média & 66,3 & 78,4 & 78,7 & 78,8 & 77,3 & 75,3 & $\hat{Y}=5,4131+11,16284 x-0,40847 x^{2}$ & 76,66 \\
\hline & & & & & & & $\mathrm{CV}(\%)$ & 13,26 \\
\hline
\end{tabular}
Agricultural Fair. 
Os valores médios foram crescentes e atingiram o ponto máximo de temperatura do ar às 10:15 h na baia de metal e às 14:49 $\mathrm{h}$ na baia de alvenaria. Embora o valor de $\mathrm{R}^{2}$ tenham sido baixo para a baia de metal, esse valor foi significativo.

A compreensão das propriedades térmicas dos materiais de construção é importante a fim de se conhecer a condutividade térmica dos mesmos (TINÔCO 2001). Ao se comparar o poder de condução do calor advindo da radiação solar direta sobre o telhado e as paredes de uma instalação, BAÊTA \& SOUZA (2010) descrevem que, o metal permite a condução de $47 \mathrm{~W} \cdot \mathrm{m}^{-1} .{ }^{\circ} \mathrm{C}$, enquanto que as edificações construídas em concreto (alvenaria) transmitem para o interior da instalação o equivalente a $1,47 \mathrm{~W} . \mathrm{m}^{-1} .{ }^{-} \mathrm{C}$.

Dessa forma, é possível compreender porque no interior das baias de metal utilizadas para acomodar os equinos, a temperatura do ar foi superior quando comparado às temperaturas verificadas no interior das baias de alvenaria, e que, nas baias de metal, os animais estavam em maior condição de desconforto térmico.

Houve diferença significativa $(p<0,0001)$ para interação entre baia e horário, nos valores de umidade relativa do ar, sendo que os menores valores foram verificados nas baias de metal. De acordo com BAÊTA \& SOUZA (2010), a umidade relativa do ar ideal deve oscilar entre 50 e $70 \%$, sendo assim, os animais estiveram expostos à UR ideal, nas baias de alvenaria (Tabela 1).

O conforto térmico está ligado a uma análise conjunta das variáveis climáticas que agem sobre uma instalação e que proporcionam uma sensação térmica, por meio do ITGU (Índice de Temperatura do Globo e Umidade). De acordo com BAÊTA \& SOUZA (2010), valores de ITGU até 74 definem condição de conforto no ambiente, de 74 a 78 é sinal de alerta, de 79 a 84 é sinal de perigo e, acima de 84 é considerado sinal de emergência. Assim, os animais alojados na baia de alvenaria, até às $8 \mathrm{~h}$ estiveram em conforto térmico, entre às $10 \mathrm{~h} \mathrm{e} 12 \mathrm{~h}$ em condição de alerta, entre $14 \mathrm{~h} \mathrm{e} 17 \mathrm{~h}$ em perigo, voltando para a faixa de alerta às $18 \mathrm{~h}$, esses animais passaram a maior parte do dia em situação de desconforto térmico.

Os animais acomodados nas baias de metal encontravam-se em conforto térmico às $8 \mathrm{~h}$ e $18 \mathrm{~h}$, porém entre às $10 \mathrm{~h}$ e $14 \mathrm{~h}$ estavam em condição classificada como perigosa. Esses valores encontrados na baia de metal estão correlacionados com a condutividade térmica dos materiais associado à cor preta com que estavam pintadas e a proximidade entre as edificações o que acabava por dificultar a ventilação natural.

De acordo com MORAES et al. (1999), o uso da cor preta em instalações rurais proporciona efeitos indesejáveis, como maior temperatura da superfície, maior emissividade e absortividade, e baixa refletividade, dessa forma, toda radiação que é incidida sobre a instalação passa a ser absorvida. Outro fator construtivo que age de forma negativa na sensação térmica é a altura do pé-direito, enquanto que nas baias de alvenaria o pé-direito era de 5 metros, nas baias de metal, essa medida era 2,15 m a 2,25 m. De acordo com BAÊTA \& SOUZA (2010), as instalações para criação animal devem ter no mínimo 2,80 m de altura, para facilitar a ventilação e reduzir a incidência da radiação dos materiais sobre os animais.

Houve diferença significativa $(p<0,0001)$ em relação à frequência respiratória (15 segundos) dos equinos em função das baias de alojamento (Tabela 2), sendo que os maiores valores foram verificados nos animais presentes nas baias de metal. Os equinos quando expostos a condições de conforto térmico apresentam a frequência respiratória (FR) variando de 8 a $16 \mathrm{mov}^{\mathrm{min}^{-1}}$ (PALUDO et al. 2002, NIEDŹWIEDŹ et al. 2013).

Tabela 2. Valores médios da frequência respiratória ( $\left.\operatorname{mov} \min ^{-1}\right)$ dos equinos ao longo do dia durante a Exposição Agropecuária.

Table 2. Mean respiratory rate (mov. min ${ }^{-1}$ ) values of equines throughout the day during the Agricultural Fair.

\begin{tabular}{|c|c|c|c|c|c|c|c|c|}
\hline \multirow{2}{*}{ Baias } & \multicolumn{6}{|c|}{ Horários (h) } & \multirow[t]{2}{*}{ Equações } & \multirow[t]{2}{*}{$\mathrm{R}^{2}(\%)$} \\
\hline & 8 & 10 & 12 & 14 & 16 & 18 & & \\
\hline Alvenaria & $34,48 b$ & $31,5 b$ & $33,6 b$ & $36,3 b$ & $35,2 b$ & $8,3 b$ & $\hat{Y}=16,99+3,0207 x-0,1085 x^{2}$ & 55,22 \\
\hline Metal & $39,1 \mathrm{a}$ & $41,8 a$ & $44,2 a$ & $41,6 a$ & $38,7 a$ & $37,9 a$ & $\hat{Y}=11,84+5,1824 x-0,2052 x^{2}$ & 32,51 \\
\hline
\end{tabular}

Médias seguidas de letras minúsculas distintas na coluna diferem entre si pelo teste $F(p<0,05)$.

A frequência respiratória dos animais foi crescente ao longo do dia, sendo que o maior valor verificado pelo ponto máximo foi às $13: 55 \mathrm{~h}$ na baia de alvenaria e às 12:37 $\mathrm{h}$ nas baias de metal. Esse fato é decorrente da constituição dos materiais que compõem as edificações, que além da condutividade térmica, possuem também o poder de amortecimento térmico. De acordo com BAÊTA \& SOUZA (2010), o 
concreto possui na sua constituição cimento e água em porções que favorecem o retardo da dissipação de calor pelo material, enquanto que o metal/aço, por não possuírem os componentes da alvenaria, não consegue armazenar o calor para dissipá-lo de forma lenta ao longo do dia, permitindo assim a passagem de calor de forma rápida para o interior da instalação, tornando o ITGU elevado (Tabela 1).

Houve diferença significativa $(p<0,0001)$ na temperatura corporal dos equinos ao se comparar as baias onde ficavam alojados, sendo superior para os animais alojados nas baias de metal (Tabela 3 ).

Os valores máximos de temperatura corporal para cabeça, tronco e garupa dos animais, nas baias de alvenaria, foram verificados às 16:24 h, 15:25 h, 15:55 h e nas baias de metal de 12:49 h, 12:39 h, 12:32 h, respectivamente. Relacionando com o ITGU, observa-se que os valores máximos foram simultâneos aos das temperaturas corporais. Indicando o desconforto térmico principalmente nos horários de maiores temperatura do ar. Nos horários em que a temperatura do ar foi mais elevada, às $12 \mathrm{~h}$ e $14 \mathrm{~h}$ (Tabela 1), a temperatura corporal dos animais também foi superior, evidenciando o maior desconforto. Após às $17 \mathrm{~h}$ a temperatura corporal dos animais, nas duas baias, não diferiu estatisticamente. De acordo com OLIVEIRA et al. (2008), embora o cavalo tenha mecanismo de dissipação de calor eficiente, há várias circunstâncias nas quais o sistema termo regulatório pode ser subjugado, resultando no desenvolvimento de hipertermia.

Tabela 3. Valores médios de temperatura corporal $\left({ }^{\circ} \mathrm{C}\right)$ dos equinos ao longo do dia durante a Exposição Agropecuária.

Table 3. Mean body temperature $\left({ }^{\circ} \mathrm{C}\right)$ values of equines during the day during the Agricultural Fair.

\begin{tabular}{|c|c|c|c|c|c|c|c|c|c|c|}
\hline \multirow[b]{2}{*}{ Baias } & \multicolumn{7}{|c|}{ Horários } & \multirow{2}{*}{ Média } & \multirow{3}{*}{ Equações } & \multirow{3}{*}{$\mathrm{R}^{2}(\%)$} \\
\hline & 8 & 10 & 11 & 12 & 14 & 17 & 18 & & & \\
\hline \multicolumn{9}{|c|}{ Cabeça } & & \\
\hline Alvenaria & $30,0 b$ & $29,8 b$ & $31,3 b$ & $31,3 b$ & $32,4 b$ & $31,9 a$ & $31,1 \mathrm{a}$ & 31,1 & $\hat{Y}=22,65+1,1583 x-0,0353 x^{2}$ & 75,83 \\
\hline Metal & $31,4 a$ & $34,3 a$ & $33,3 a$ & $35,2 a$ & $34,4 a$ & $32,3 a$ & $32,0 \mathrm{a}$ & 33,3 & $\hat{Y}=15,13+3,020 x-0,1177 x^{2}$ & 73,68 \\
\hline Média & 30,7 & 32,0 & 32,4 & 33,2 & 33,4 & 32,1 & 31,5 & & CV (\%) & 6,20 \\
\hline \multicolumn{11}{|c|}{ Tronco } \\
\hline Alvenaria & $28,9 b$ & $29,2 b$ & $31,3 b$ & $30,8 b$ & $32,3 b$ & $31,3 a$ & $30,4 a$ & 30,6 & $\hat{Y}=17,83+1,8263 x-0,0592 x^{2}$ & 81,32 \\
\hline Metal & $30,5 a$ & $34,1 \mathrm{a}$ & $33,1 \mathrm{a}$ & $35,4 a$ & $33,5 a$ & $31,6 a$ & $30,4 a$ & 32,7 & $\hat{Y}=8,73+4,0643 x-0,1606 x^{2}$ & 83,09 \\
\hline Média & 29,7 & 63,3 & 32,2 & 33,1 & 33,1 & 31,4 & 30,4 & & CV (\%) & 6,06 \\
\hline \multicolumn{11}{|c|}{ Garupa } \\
\hline Alvenaria & $28,0 b$ & $28,1 b$ & $31,0 b$ & $30,3 b$ & $31,7 b$ & $31,4 a$ & $29,8 a$ & 30,0 & $\hat{Y}=15,81+1,9825 x-0,0622 x^{2}$ & 78,37 \\
\hline Metal & $30,1 \mathrm{a}$ & $33,6 a$ & $33,0 a$ & $34,3 a$ & $33,4 a$ & $30,8 a$ & $30,2 a$ & 32,2 & $\hat{Y}=10,92+3,6350 x-0,1449 x^{2}$ & 80,40 \\
\hline Média & 29,1 & 30,9 & 32,1 & 32,4 & 32,6 & 31,1 & 30,0 & & CV (\%) & 6,06 \\
\hline
\end{tabular}

Tabela 4. Valores médios da frequência de ocorrência (\%) dos parâmetros comportamentais dos equinos, em função das baias e dos horários de observação.

Table 4. Mean frequency of occurrence (\%) values of the behavioral parameters of the equines, according to the stall type and observation schedules.

\begin{tabular}{|c|c|c|c|c|c|c|c|c|}
\hline \multirow{2}{*}{ Comportamento } & \multicolumn{2}{|c|}{ Baias } & \multicolumn{4}{|c|}{ Horário } & \multirow{2}{*}{ Equação } & \multirow{2}{*}{ CV $(\%$} \\
\hline & Alvenaria & Metal & 8 & 12 & 14 & 18 & & \\
\hline Defecação & 4,9 & 4,9 & 7,5 & 5,8 & 4,5 & 1,6 & $\hat{Y}=9,6715-1,9032 x$ & 68,33 \\
\hline Alimentação & 3,5 & 4,2 & 4,1 & 4,2 & 4,3 & 2,7 & $\hat{Y}=4,9082-0,4082 x$ & 69,49 \\
\hline Micção & 4,3 & 5,4 & 5,1 & 6,4 & 5,0 & 2,8 & $\hat{Y}=6,9655-0,8366 x$ & 66,42 \\
\hline Ingestão de água & 9,2 & 8,7 & 3,3 & 11,2 & 15,6 & 5,9 & $\hat{Y}=-15,9444+23,08 x-4,37 x^{2}$ & 73,40 \\
\hline Relincho & 3,3 & 3,5 & 3,4 & 3,6 & 5,0 & 1,7 & $\hat{Y}=4,3965$ & 65,97 \\
\hline Agitação & 2,9 & 3,3 & 2,9 & 5,2 & 3,4 & 1,0 & $\hat{Y}=5,0472$ & 70,56 \\
\hline
\end{tabular}

Não houve diferença significativa $(p=0,9918)$ entre o comportamento dos animais acomodados nas 
baias de metal e alvenaria (Tabela 4). A frequência de defecação foi a mesma entre as baias, com maior ocorrência às $8 \mathrm{~h}$ da manhã, devido ao contato inicial do dia com pessoas desconhecidas. Segundo ARGENZIO (2006), animais com medo defecam frequentemente, presumivelmente pela facilitação do reflexo por centros no cérebro.

A frequência do consumo de água foi maior $(p=0,9401)$ nos horários em que a temperatura do ar também foi maior (Tabela 1), bem como a frequência de micção às $12 \mathrm{~h}$ e $14 \mathrm{~h}$ diminuindo durante $\mathrm{o}$ dia. $\mathrm{O}$ fato dos animais ingerirem água e urinarem está relacionado ao aumento da temperatura do ar e não a uma alteração do comportamento como resposta ao medo do tratador ou do público visitante da exposição.

$\mathrm{O}$ ato de relinchar, por exemplo, que é um som longo, alto e agudo, é utilizado pelos cavalos para chamar a atenção sobre algo ou alguém, é uma expressão normal do comportamento, ao mesmo tempo que demonstra a reatividade dos equinos a determinadas circunstâncias (CALVIELLO et al. 2015). Na Tabela 4, observa-se que os animais de ambas as baias relincharam com maior frequência $(p=0,6312)$ às $14 \mathrm{~h}$, horário em que foi registrado a maior temperatura. Os fatores ambientais mais estressantes para os cavalos estão relacionados ao transporte, o exercício, e condições adversas de temperatura, umidade do ar e ruído (NAZARENO et al. 2015). A agitação dos animais foi maior nos horários de $12 \mathrm{~h} \mathrm{e} 14 \mathrm{~h}$ (Tabela 4), mesmo horário da maior frequência de relinchos, o que pode confirmar que os animais relinchavam possivelmente pelo desconforto térmico.

\title{
CONCLUSÃO
}

O ambiente climático das baias influenciou nas variáveis fisiológicas e no aumento do consumo de água e micção dos animais. A ansiedade ou medo foram as características que influenciaram o aumento da defecação e demais respostas comportamentais dos animais, no início do julgamento em pista. Os animais acomodados nas baias de metal apresentaram maior desconforto térmico.

\section{AGRADECIMENTOS}

\author{
À FAPEMIG, CAPES e CNPq.
}

\section{REFERÊNCIAS}

ARGENZIO RA. 2006. Motilidade gastrintestinal. In: REECE WO (Ed.). Dukes: Fisiologia dos animais domésticos. 12.ed. Rio de Janeiro: Guanabara Koogan. p.362-373.

BAÊTA FC \& SOUZA CF. 2010. Ambiência em edificações rurais: conforto animal. 2.ed. Viçosa: Editora UFV. 269p.

BROOM DM. 1991. Animal welfare: concepts and measurement. Journal of Animal Science 69: 4167-4175.

BUFFINGTON DE et al. 1981. Black globe humidity index (BGHI) as comfort equation for dairy cows. Transaction of the ASAE 24: 711-714.

CALVIELLO RF et al. 2015. Avaliação da reatividade de equinos na presença de estímulo sonoro desconhecido. Brazilian Journal of Veterinary Research and Animal Science 52: 167-172.

CINTRA AGC. 2010. O Cavalo: Características, Manejo e Alimentação. 1.ed. São Paulo: Editora Roca. 384p.

HUSS R \& SILVA FC. 2013. Feiras agropecuárias, vitrines do agronegócio brasileiro. Disponível em: http://.www.grassa no.com.br/publicacao.php?lang=ptr\&id=213\&id_categoria=8\#.WEAZ4X1ZjYY. Acesso em: 03 mar. 2014.

MORGAN K. 1996. Short-term thermoregulatory responses of horses to brief changes in ambient temperature. Uppsala: Swedish University of Agricultural Sciences. p. 9-51.

MORAES SRP et al. 1999. Conforto térmico em galpões avícolas, sob coberturas de cimento-amianto e suas diferentes associações. Revista Brasileira de Engenharia Agrícola e Ambiental 3: 89-92.

NAZARENO AC et al. 2015. Ambiência no Transporte de Equinos e os Efeitos nas Respostas ao Estresse. Journal of Animal Behaviour and Biometeorology 3: 73-80.

NIEDŹWIEDŹ A et al. 2013. Plasma total antioxidant status in horses after 8-hours of road transportation. Acta Veterinaria Scandinavica 55: 1-4.

OLIVEIRA LA et al. 2008. Estudo de respostas fisiológicas de equinos sem raça definida e da raça quarto de milha às condições climáticas de Teresina, PI. Ciência Animal Brasileira 9: 827-838.

PALUDO GR et al. 2002. Efeito do estresse térmico e do exercício sobre parâmetros fisiológicos de cavalos do exército brasileiro. Revista Brasileira de Zootecnia 31: 1130-1142.

PIMENTEL MM et al. 2013. Manejo Nutricional de Equinos utilizados em provas de vaquejada no Rio Grande do Norte, Brasil. Acta Veterinaria Brasilica 7: 61-65.

TINÔCO IFF. 2001. Avicultura Industrial: Novos Conceitos de Materiais, Concepções e Técnicas Construtivas Disponíveis para Galpões Avícolas Brasileiros. Revista Brasileira de Ciência Avícola 3: 1-26. 